\title{
Uso de la tierra y crecimiento de la población en el oriente del estado de México
}

\section{Use of the earth and growth of the population in the east of the state of Mexico}

Genaro Aguilar-Sánchez ${ }^{1}$, Miriam Julián-Santiago²

Aguilar-Sanchéz, G; Julián-Santiago, M. Uso de la tierra y crecimiento de la población en el oriente del estado de México. Tecnología en Marcha. Vol. 32, Especial. XIII CLIA. Abril 2019. Pág 57-63.

DOI: https://doi.org/10.18845/tm.v32i7.4260 


\title{
Palabras clave
}

Cambio de uso de la tierra; población; México.

\section{Resumen}

El oriente del estado de México en los últimos años ha tenido un gran crecimiento de núcleos urbanos, cambiando el uso de los recursos naturales. El objetivo es caracterizar el uso de la tierra y relacionarlo con el crecimiento de la población, para diagnosticar el impacto de la población en la microcuenca de los ríos Coatepec y El Manzano. Para lo anterior se caracterizaron ocho usos de la tierra. Siendo el uso agrícola el más representativo de la cuenca. A través de ortofotos digitales e imágenes de satélites Landsat 7, se generaron los mapas del uso de la tierra para los años 1999 y 2015. Los resultados obtenidos fueron la reducción de hectáreas destinadas al uso: agrícola, vegetación menos densa y, baldío; mientras que se incrementaron hectáreas para los uso urbano, mina y matorral. Los cambios en el uso de la tierra, se relacionan con el crecimiento de la población de los municipios presentes del oriente del Estado de México: Chicoloapan, Ixtapaluca y Texcoco, con una tasa de crecimiento en porciento de 10.87, 4.4 y 1.2 respectivamente. Se recomienda diversificar los cultivos, implementar un sistema de pastoreo controlado en áreas de matorral, así como un plan de manejo para 800 hectáreas de bosque. Establecer obras de contención para el control de escurrimientos y disminución de arrastres en los ríos Manzano y Coatepec

\section{Keywords}

Change in land use; population; Mexico.

\begin{abstract}
The east of the state of Mexico in recent years has had a large growth of urban centers, changing the use of natural resources. The objective is to characterize the use of the land and relate it to the population growth, to diagnose the impact of the population in the microbasin of the Coatepec and El Manzano rivers. For the above, eight uses of the land were characterized. Being the agricultural use the most representative of the basin. Through digital orthophotos and images from Landsat 7 satellites, maps of land use were generated for the years 1999 and 2015. The results obtained were the reduction of hectares destined for use: agricultural, vegetation less dense and, wasteland; while hectares were increased for urban use, mine and scrub. The changes in land use are related to the population growth of the municipalities present in the east of the state of Mexico: Chicoloapan, Ixtapaluca and Texcoco, with a growth rate in percent of 10.87, 4.4 and 1.2 respectively. It is recommended to diversify the crops, implement a controlled grazing system in scrub areas, as well as a management plan for 800 hectares of forest. Establish containment works for the control of runoff and reduction of trawls in the Manzano and Coatepec rivers
\end{abstract}

\section{Introducción}

La población en México ha aumentado considerablemente en las últimas décadas hasta alcanzar, en el año 2010, una población total de 112.3 millones de habitantes. Aunado a esto, la desigualdad social se hace cada vez más evidente pues, del total de la población; el 46\% vive en condición de pobreza y el 9.5\% en pobreza extrema.[1] Las cifras mencionadas contrastan considerablemente si las comparamos con la riqueza y biodiversidad de los recursos naturales presentes en el país, significa entonces que, innegablemente se ha hecho un uso inadecuado y desmedido de estos recursos. 
Una de las regiones donde mayor presión se ejerce sobre el medio natural es la Cuenca del Valle de México, cuya población en 2010 alcanzó un total de 20.11 millones, es decir, el 19\% de la población total del país. La presente investigación se enfoca en el estudio de la microcuenca de los ríos Coatepec y El Manzano ubicados en los municipios de Chicoloapan, Ixtapaluca y Texcoco en el oriente del Estado de México. Se caracterizaron los usos de la tierra y los cambios ocurridos en un periodo de 15 años, así como el impacto que genera el crecimiento poblacional en la cuenca. Objetivo. Delimitar y caracterizar el uso actual de la tierra en la microcuenca de los ríos Coatepec y El Manzano de 1999 a 2015, ubicada al oriente de estado de México.

\section{Materiales y métodos}

La delimitación de la microcuenca se realizó utilizando el Modelo Digital de Elevación de INEGI y las curvas a nivel para generar la red de corrientes con la extensión Spatial Analyst de ArcGis. En la caracterización de los recursos naturales se usa la propuesta de [2]. La topografía, edafología y geología presentes en la microcuenca de estudio, se obtuvieron de las correspondientes cartas de Chalco con clave E14B36 de INEGI [3] escala 1:50,000. Para el clima, se utilizó el shp de climas del portal geoinformación de la Comisión Nacional para el Uso y el Conocimiento de la Biodiversidad [4], escala 1:1, 000,000.

Caracterización morfométrica. Se determinaron algunas características morfométricas de la microcuenca como definen,[5],[6]y[7]: Área, perímetro, longitud, índice de forma, coeficiente de compacidad, tiempo de concentración, red de drenaje, número de orden de corrientes, densidad de drenaje, relación de bifurcación, perfil longitudinal, pendiente del cauce principal, pendiente media de la cuenca, curva hipsométrica y altura media de la cuenca. Dichos parámetros se obtuvieron con una combinación de los SIG y programación en Microsoft office Excel empleando las fórmulas que los autores refieren.

Uso del suelo y vegetación. Para generar el mapa de Uso del suelo y Vegetación, se siguió la metodología del levantamiento fisiográfico que propone [8]. Después de la delimitación de la zona de estudio, posteriormente se obtuvieron las fotografías aéreas en blanco y negro de [9] para estudiar el uso de la tierra en ese año, así como imágenes de satélite google earth del año 2015 para estudiar el uso actual de la tierra. Para el análisis de la expansión de la mancha urbana, se realizó la sobre-posición de los mapas generados para el año 1999 y 2015, y se compararon las superficies ocupadas y los porcentajes que abarcan en la cuenca. Se analizaron también los censos de población y vivienda del Estado de México para los municipios de San Vicente Chicoloapan, Ixtapaluca y Texcoco con el fin de relacionar el crecimiento poblacional, los cambios ocurridos, así como los servicios con los que cuenta la población para satisfacer sus necesidades primordiales.

\section{Resultados y discusión}

En el oriente del Estado de México, en los municipios de San Vicente Chicoloapan, Ixtapaluca y Texcoco se ubica la microcuenca de los ríos Coatepec y el Manzano pertenece a la Región Hidrográfica 26-Pánuco y región hidrológica administrativa del Valle de México mejor conocida como Cuenca del Valle de México. La Cuenca del Valle de México está compuesta por siete subcuencas, dentro de las cuales se encuentra la del ex Lago de Texcoco. El área de estudio se encuentra ubicado geográficamente entre los 98 46'0.13" y 9854'46.64" longitud oeste y entre los $19^{\circ} 23^{\prime} 0.16^{\prime \prime}$ y $19^{\circ} 25^{\prime} 57.28^{\prime \prime}$ latitud norte, se localiza dentro de la Provincia Fisiográfica Eje Neovolcánico, en la porción central de la Subprovincia Fisiográfica Lagos y Volcanes de Anáhuac. Se encuentra rodeado por cadenas montañosas de origen volcánico, entre los que destacan las sierras de las cruces, el Popocatépetl y el Iztaccíhuatl. La geología 
de la microcuenca está representada principalmente por materiales de tipo ígneo, reportando 2 tipos de rocas: andesitas y brecha sedimentaria (60\%). También se tiene la presencia de material lacustre y aluvión con un 17.7\%. La edafología de la microcuenca está compuesta por cambisol, feozem, litosol y regosol, [3]

Hidrología. El área de estudio se encuentra ubicada en la región hidrológica número 26 denominada Pánuco, dentro de la subcuenca del Lago de Texcoco (RH26DN) y Zumpango, la cual forma parte de la Cuenca del Río Moctezuma. Existen dos causes o ríos intermitentes que son torrenciales en la época de lluvias y, por su longitud sobresalen los ríos El manzano y Coatepec. Los ríos corren en dirección Este-Oeste para unir su afluencia al noreste de la cabecera municipal, pasando por el dren Chimalhuacán I y II. Ambos ríos contienen aguas residuales domesticas e industriales, los cuales originan contaminación en la zona y provocan desbordamiento en las épocas de lluvia.

Los tipos de clima presente en la microcuenca de estudio son: Templado Sub húmedo con temperatura media anual entre 12 y $18^{\circ} \mathrm{C}$ y temperatura del mes más frío entre $-3^{\circ} \mathrm{C}$ y $18^{\circ} \mathrm{C}$; y semifrío subhúmedo con temperatura media anual entre 5 y $12^{\circ} \mathrm{C}$. La precipitación en la parte baja y media de la microcuenca es de 600 a 650 mm anuales, esta es la más representativa. En la parte alta, entre los 2600 msnm a 3400msnm, la precipitación va de los 650 a 700mm anuales, la temperatura en la microcuenca de estudio va desde los $12^{\circ} \mathrm{C}$ en las partes más altas hasta los $17^{\circ} \mathrm{C}$ en las partes bajas.

Caracterización socioeconómica de la microcuenca Coatepec y El Manzano. El Estado de México es la entidad más poblada con 16.1 millones de habitantes para el año 2015, [1] en, representa el 13.5 \% de la población nacional. La población de los municipios que abarcan la microcuenca de estudio se muestra en el cuadro 1.

Cuadro 1. Población de los municipios presentes en la microcuenca de estudio

\begin{tabular}{|c|c|c|c|c|c|}
\hline \multirow{2}{*}{ Municipio } & \multicolumn{4}{|c|}{ Población total } & Tasa de crecimiento \\
\hline Chicoloapan & 2000 & 2005 & 2010 & 2015 & 15 años \\
\hline Ixtapaluca & 297570 & 470035 & 175053 & 204107 & $10.87 \%$ \\
\hline Texcoco & 204102 & 209308 & 235151 & 240749 & $4.4 \%$ \\
\hline
\end{tabular}

Fuente: Cuaderno Estadístico del Estado de México, INEGI 2016.

Aunque el municipio de Ixtapaluca tiene la población más alta, la tasa de crecimiento nos indica que Chicolapan es el que más ha crecido en 15 años. Este municipio también es el que mayor impacto tiene sobre la cuenca, pues tiene mayor superficie dentro de ella.

En términos específicos, según las localidades dentro de la cuenca: 8 localidades de Chicoloapan más la cabecera municipal, 7 localidades de Ixtapaluca y solo una localidad del municipio de Texcoco, nos dan un total de 175, 897 habitantes dentro de la microcuenca de los ríos Coatepec y El Manzano. En el cuadro 3 se presenta los paramentos obtenidos para la cuenca. 
Cuadro 2. Superficie y porcentaje de los municipios de la microcuenca de estudio.

\begin{tabular}{|c|c|c|c|c|}
\hline Municipio & $\begin{array}{c}\text { Superficie } \\
\left(\mathrm{km}^{2}\right)\end{array}$ & $\begin{array}{c}\text { Superficie dentro de la } \\
\text { microcuenca }\left(\mathrm{Km}^{2}\right)\end{array}$ & $\begin{array}{c}\text { \% del área municipal } \\
\text { que aporta a la cuenca }\end{array}$ & $\begin{array}{c}\text { \% del área total de } \\
\text { la cuenca }\end{array}$ \\
\hline $\begin{array}{c}\text { San Vicente } \\
\text { Chicoloapan }\end{array}$ & 60.89 & 27.91 & 45.8 & 57.8 \\
\hline Ixtapaluca & 315.1 & 14.003 & 4.4 & 29 \\
\hline Texcoco & 418.69 & 6.354 & 1.5 & 13.2 \\
\hline
\end{tabular}

Fuente: Elaboración propia.

Cuadro 3. Parámetros relativos al área y la longitud de la cuenca.

\begin{tabular}{|c|c|c|}
\hline \multirow{2}{*}{ Área de la cuenca } & ha & $\mathrm{km}^{2}$ \\
\cline { 2 - 3 } & 4828.2 & 48.28 \\
\hline \multirow{2}{*}{ Perímetro } & $\mathrm{m}$ & $\mathrm{km}$ \\
\cline { 2 - 3 } & 35231.6 & 35.232 \\
\hline Longitud de la Cuenca & 15948 & 15.9 \\
\hline Longitud rio Coatepec & 18450.6 & 18.45 \\
\hline Longitud rio El Manzano & 12612.04 & 12.6 \\
\hline Canal & 3653.4 & 3.65 \\
\hline
\end{tabular}

Fuente: Elaboración propia

Uso de la tierra del año 1999 y 2015 .Se clasificaron 8 usos de la tierra. El siguiente cuadro muestra la superficie y porcentaje de dichos usos.

Cuadro 4. Usos de la tierra para el año 1999- 2015.

\begin{tabular}{|c|c|c|c|c|c|}
\hline $\begin{array}{c}\text { Usos de la tierra } \\
1999\end{array}$ & Área (ha) & $\begin{array}{c}\text { \% del total de la } \\
\text { cuenca }\end{array}$ & $\begin{array}{c}\text { Uso actual la } \\
\text { tierra 2015 } \\
\text { (ha) }\end{array}$ & $\begin{array}{c}\text { \% del total } \\
\text { de la cuenca }\end{array}$ & $\begin{array}{c}\text { Variación } \\
\text { en \% }\end{array}$ \\
\hline Agrícola & 2060.4 & 42.7 & 1624.8 & 33.6 & -9.0 \\
\hline Baldíos & 172.357 & 3.6 & 99.1 & 2.1 & -1.5 \\
\hline Bosque & 902.5 & 18.7 & 862.4 & 17.9 & -0.8 \\
\hline Sin vegetación aparente & 189.0 & 3.9 & 206.1 & 4.3 & +0.4 \\
\hline Minas & 156.7 & 3.2 & 300.8 & 6.2 & +3.0 \\
\hline Otros & 24 & 0.5 & 23.0 & 0.5 & 0.0 \\
\hline Urbano & 294 & 6.1 & 860.7 & 17.8 & +1.7 \\
\hline Vegetación menos densa & 1029.4 & 21.3 & 852.3 & 17.6 & -3.7 \\
\hline
\end{tabular}

Fuente: Elaboración propia 
Se aprecia que el uso agrícola en el 2005, mantiene mayor presencia en la microcuenca con una superficie de 1624.8 hectáreas, es decir 394 hectáreas menos que en el año 1999. En seguida el área con tiene una superficie de 862.4 ha, ocupando así el segundo lugar con $17.9 \%$ de la superficie total de la cuenca. El uso urbano actualmente se ubica en el tercer lugar de importancia con una superficie de 860.7 hectáreas que representa el 17.8\% del área de la cuenca, tan solo un porcentaje antes de la vegetación menos densa.

El uso agrícola de la tierra se redujo en 435. 6 hectáreas, fue el uso que tuvo un mayor decremento equivalente a un 9\%. Dichas superficies pasaron a ser utilizadas para la construcción de colonias y unidades habitacionales debido a la cercanía con la zona urbana y las vías de comunicación. En el aspecto forestal, la superficie del bosque se redujo en 40.1 hectáreas, esto es el $0.8 \%$ con respecto a la superficie total. Por otro lado, la vegetación menos densa se redujo en 177 hectáreas, esto es 3.7\%, por lo que ocupa el segundo lugar de los usos con mayores decrementos.

\section{Conclusiones}

Las tierras con suelos de tipo feozem calcárico y háplico son aptos para cultivos agrícolas, por lo que no se recomienda que la urbanización ocupe dichas áreas. El regosol eutrico y litosol, se podrían destinar también para el uso urbano, es decir, el crecimiento inevitable de la zona urbana en la microcuenca podría ocupar algunas hectáreas de dicho tipo de suelos. En el suelo cambisol con uso forestal, se propone la implementación de un plan de manejo para aprovechar de manera sustentable las 800 hectáreas aproximadamente de bosque.

Los cambios de uso de la tierra, tienen como causa principal el incremento de la población, pues de los municipios que abarcan la cuenca, Chicoloapan cuya superficie dentro de la microcuenca es mayor, tiene el más alto crecimiento poblacional con una tasa de $10.87 \%$ de 2000 a 2015. Además de que el uso que más se incrementó fue el urbano. Se considera prioritario mantener la actividad agrícola en la región y diversificar la producción de cultivos. Se propone una diversificación de los cultivos que ya se siembran e implementar la producción de hortalizas que se adapten a climas templados, con ciclos de crecimiento menores de 5 meses, compensando los requerimientos de precipitación con riego, especies como: acelga, calabacita, cebolla, cilantro, espinaca, lechuga, etc., destinado para el consumo local-familiar de la zona. Sembrar y/o alternar especies de leguminosas como el chícharo, el haba, el garbanzo, incluso el amaranto, pues son cultivos que se adaptan al clima templado, con ciclos de maduración promedio de 5 meses y requerimientos de humedad mínima de $150 \mathrm{~mm}$ y promedio de $600 \mathrm{~mm}$. Dichos cultivos además de fijar nitrógeno al suelo mejorando su calidad, su consumo aporta nutrientes importantes para la buena alimentación de las personas.

En laderas con pendientes menores a 15\%, correspondiente al uso pastizal-matorral, se recomienda implementar el cultivo de nopal para consumo (verdura) y el maguey (pulquero) para favorecer la alimentación y economía de las familias, al mismo tiempo que funcionan como barreras vivas para el control de la erosión de suelos si se siembran a lo largo de bordos-zanjas siguiendo las curvas de nivel, terrazas individuales o en fajas entre parcelas. Para los ríos Coatepec y El Manzano se recomienda establecer obras de contención para el control de los escurrimientos superficiales y disminución del arrastre de sedimentos aguas abajo.

\section{Referencias}

[1] Instituto Nacional de Estadística Geografía e Informatica (INEGI), Censo de población y vivienda del estado de México, Ags, Ags., México,2016

[2] G.Aguilar, Planeación del uso de los recursos natuarales. Chapingo, Texcoco, Edo. de México: UACh-C.R, 2003 
[3] Instituto Nacional de Estadística Geografía e Informatica (INEGI), Carta Topográfica, Edafología y Geología, Chalco de Díaz Covarrubias, Clave E14B31, Escala 1:50,000. 2009

[4] Comisón Nacional del Agua (CONAGUA), (15 de Enero de 2015). [Online].Available:

http://www.conagua.gob. $m x /$ Contenido.aspx?n1=3\&n2=60\&n3=89. Obtenido de Sistema Nacional de Información del Agua (SINA) - Estadísticas del Agua en México 2008: http://www.conagua.gob.mx/Contenido. aspx?n1=3\&n2=60\&n3=89,

[5] F. Rodríguez, Escurrimiento Superficial. Chapingo, Estado de México: PATENA AC. 1981.

[6] R.Springal, Hidrología. México, D.F: UNAM,1970

[7] G. Monsalve, Hidrología en Ingeniería. México: Escuela Colombiana de Ingeniería, 1995

[8] C. A. Ortiz, \& H, Cuanalo de la Cerda, Levantamiento fisiográfico del área de influencia de Chapingo (la cartografía de tierras erosionadas). Chapingo, México: Colegio de Postgraduados, 1977

[9] Instituto Nacional de Estadística Geografía e Informatica (INEGI), ( Ortofotos Digitales blanco y negro, resolución 1.5, datum ITRF 92, Proyección UTM. Abril de 1999)

[10] Consejo Estatal de Población (COESPO), Cuaderno Estadístico del Estado de México. Gobierno del Estado de México. [Online]. Available : https://goo.gl/zsQ8eH 